\title{
O PAPEL SOCIAL DO DESIGN DE MODA NAS MANIFESTAÇÕES DE IDENTIDADE DE GÊNERO CONTEMPORÂNEAS
}

Mariana Hennes

\begin{abstract}
Resumo: O design de moda, embora venha sendo gradativamente inserido no contexto social, especialmente após sua institucionalização como campo de Conhecimento, ainda é constantemente associado a aspectos essencialmente visuais e decorativos, permanecendo como frivolidades superficiais e elitistas no imaginário popular de boa parte da população. No entanto, o papel social da moda evidencia-se hoje quando passa a integrar o processo de transformação social, colocando em discussão os tradicionais sistemas normativos de gênero e dão espaço a novas formas de entender os tipos de representação contemporâneos. Assim, esse trabalho tem como objetivo discutir o papel da moda nesse contexto, impulsionando uma abertura de pensamento sobre gêneros na medida em que provoca, na sociedade, um momento de reflexão sobre as formas de transgressão sociais.
\end{abstract}

Palavras-chave: design de moda, identidade de gênero, representação social

\section{INTRODUC̣ÃO}

Design de produto, design gráfico, design de moda, design de interiores, webdesign. Usando uma definição abrangente, podemos dizer que o design está em tudo a nossa volta, informando, identificando, decorando, seduzindo, divertindo, sinalizando, organizando, protegendo e facilitando nossas vidas. Está nas coisas que vestimos, em tudo que lemos e usamos; está inserido no nosso cotidiano através de artefatos diversos, sejam eles efêmeros, duráveis, virtuais ou palpáveis.

Apesar de ser possível ensaiar uma definição para o que é design e qual o papel social do designer na contemporaneidade, estabelecer um entendimento claro e objetivo para esses questionamentos mostra-se uma tarefa difícil, já que as respostas vêm sendo constantemente formuladas e transformadas ao longo dos anos, acompanhando as mudanças de paradigmas sociais, culturais e os avanços tecnológicos.

De forma análoga aos outros segmentos do design, o Design de Moda acompanha esse processo de constante reinvenção. A saber, a roupa que vestimos, bem como os acessórios que usamos e todas as outras formas de modificar/transformar nosso corpo (corte de cabelo, maquiagem, tatuagem, implantes, etc) têm funções múltiplas, revelando, além das informações sobre nosso humor ou sobre o tempo, muito sobre nossa personalidade, nossa identidade, nossa relação com o corpo que possuímos, nosso estilo de vida, nossas crenças e nossos posicionamentos acerca de determinados valores.

Para Crane (2006, p. 456) a moda pode ser compreendida como um meio de comunicação não-verbal e visual, o qual tem o poder de "fazer declarações sociais subversivas”. Assim, ao serem projetadas para uso em ambientes públicos, as peças de 
vestuário transformam-se em veículos de expressão do ser para com os outros, e não somente para com ele próprio. Nesse contexto, é possível dizer que, por se tratar de uma forma de apresentação social silenciosa (embora de grande representatividade), as escolhas individuais sobre o que vestir (bem como utilizar as outras formas de expressão que são abarcadas pelo universo da moda) perpassam por uma série de fatores de diferentes naturezas.

Assim, ao analisarmos como se dá a concepção do design de produto com valor de moda, devemos considerar a existência de dois importantes aspectos: o primeiro é o intangível, que compreende as tendências, atitudes, valores e estilos de vida; e o segundo é o tangível, que se preocupa com o corpo, a sua forma, a ergonomia, os materiais e os fatores sensoriais (ROCHA, 2006).

Embora seja possível racionalizar essa dicotomia, a subjetividade da moda e as particularidades físicas do corpo humano estão tão intrinsecamente conectadas, que faz sentido pensar nas peças de moda-vestuário como a segunda pele do indivíduo. É através do corpo que os indivíduos apresentam e representam as suas relações sociais e comunicam sua identidade, não sendo o corpo entendido como "um mero veículo ou suporte da roupa”, mas elemento fundamental na sua materialização (OLIVEIRA apud CASTILHO, 2004, p. 12). Nesse sentido, os artefatos de moda-vestuário devem acompanhar as mudanças de aparência do corpo para adequar-se às expectativas formais e estéticas dos seus usuários.

\section{CORPO, MODA E REPRESENTAÇÃO SOCIAL}

Ao estabelecer que o ser humano é naturalmente mutante, podemos dizer que, desde o momento que nasce, seu corpo entra em processo de constante transformação, e na medida em que evolui pode ainda passar por mudanças mais ou menos perceptíveis, inclusive produzidas artificialmente. Assim, Greiner (2005, pág. 36) alude que "o corpo não pode ser entendido com um produto pronto e muda de estado no momento em que ocorre uma ação".

Para Fabri (2015, p. 47), o corpo humano pode ser considerado "um rascunho, uma matéria-prima de geometria variável, que pode ser redesenhada de uma forma diferente daquela configuração natural". Portanto, gêmeos siameses que nascem fisicamente ligados um ao outro, necessitam de intervenções que afetam não só sua saúde, mas permitem uma vida mais autônoma e livre; analogamente, uma mulher insatisfeita com o tamanho dos seus seios pode decidir aumentá-los ou diminuí-los numa ação que afetará não apenas seu corpo, mas sua autoestima - sua forma de encarar a vida. De natureza permanente ou temporária, a alteração do corpo atua, antes de qualquer coisa, na imagem interior que o ser modificado tem de si mesmo e na maneira como este se reconhece no contexto social em que vive, conforme explica Le Breton (2003):

Ao mudar o corpo, o indivíduo pretende mudar sua vida, modificar seu sentimento de identidade. A cirurgia estética não é a metamorfose banal de uma característica física no rosto ou no corpo; ela opera, em primeiro lugar, no imaginário e exerce uma incidência na relação do indivíduo com o mundo (LE BRETON, 2003, p. 30).

Segundo Le Breton (2003), o corpo é, para o ser contemporâneo, uma espécie de primeira apresentação de si mesmo, e, portanto, a preocupação em modelar sua aparência, ocultando aspectos considerados desfavoráveis para a imagem que deseja construir (como envelhecimento ou fragilidade), torna-se cada vez mais constante. No entanto, algumas mudanças (ou configurações) físicas e de comportamento podem causar impactos muito mais significativos, tanto na identidade do indivíduo quanto na maneira como a sociedade lida com essa transformação. 
Segundo Fabri (2015, p. 47), na sociedade contemporânea podemos enxergar o corpo humano como um "produto" capaz de ser moldado, transformado, aprimorado e reconfigurado por meio de técnicas diversas que vão desde a prática de exercícios físicos a tatuagens, implantes cutâneos, chegando até "cirurgias de transgenitalização para redesignação de gênero com a mudança da anatomia sexual natural".

Por interferir de maneira tão contundente nos aspectos subjetivos da vida humana, essas mudanças do corpo geralmente são realizadas a fim de encontrar um denominador comum na forma como o indivíduo é, se vê, aspira ser, e na sua expectativa de representação social, ou seja, em como os outros o veem.

Analogamente ao papel social da medicina nesses casos de transformação corpórea, a moda exerce função fundamental na medida em que, segundo Castilho \& Moura (apud FABRI, 2015, p. 45) também "cria novas formas para que o corpo se apresente socialmente", legitimando sua identidade.

Tradicionalmente, o mecanismo da moda quase sempre se apoiou na classificação binária de gênero (masculino e feminino) para estabelecer padrões estéticos e formais relacionados ao vestuário. Crane (2006) alude que a moda exerce, de modo geral, um papel significativo nos tipos de representações sociais externalizadas pelos indivíduos, com claras diferenças entre homens e mulheres:

[...] as roupas da moda são usadas para fazer uma declaração sobre classe e identidades sociais, mas suas mensagens principais referem-se às maneiras pelas quais mulheres e homens consideram seus papeis de gênero, ou a como se espera que eles o percebam

(CRANE, 2006, p. 47).

Porém, segundo a autora (CRANE, 2006, p. 50), desde o final do século XX essa dicotomia rígida sobre identidade de gênero vem sendo revista, trazendo à luz novas reflexões acerca da diversidade que envolve os seres humanos. Para a autora (CRANE, 2006), foi a partir da afirmação de Michel Foucault de que "as percepções de gênero não são fixas, mas efeitos de discursos médicos e psiquiátricos", que tais discussões ganharam impulso, representando uma mudança na visão de mundo que vinha sendo construída e atuando na diminuição da intolerância e preconceitos acerca do tema.

Hoje se evidencia que uma classificação de gênero restrita não atende à complexidade da condição humana. Ao perceber que tal aspecto, por tanto tempo entendido com imutável, pode ganhar novas ramificações e interpretações, faz sentido se discutir qual o papel da moda na construção da identidade do indivíduo transgênero (ou não cis-gênero).

\section{IDENTIDADE DE GÊNERO E O PROCESSO DE RESSEMANTIZAÇÃO CORPÓREA POR MEIO DA MODA}

No início de 2014, uma das redes sociais mais populares da atualidade, o Facebook, fomentou uma discussão interessante ao oferecer ao público nos EUA, 56 opções de identidade de gênero para o perfil de usuário, além de feminino e masculino (Figura 01). Diferentemente da classificação de sexo do indivíduo (que se refere às características biológicas e inclui a configuração de cromossomos, hormônios, unidades reprodutivas e a anatomia interna e externa), e da orientação sexual (que indica por quais gêneros ela sente-se atraída, seja física, romântica e/ou emocionalmente); a identidade de gênero está mais ligada aos aspectos simbólicos de como a pessoa se identifica e se reconhece no contexto social (ARAGÃO, 2013). 
Figura 01: Opções de identidade de gênero no Facebook, após atualização ocorrida em 2014 para perfis americanos (Oremus, 2014).

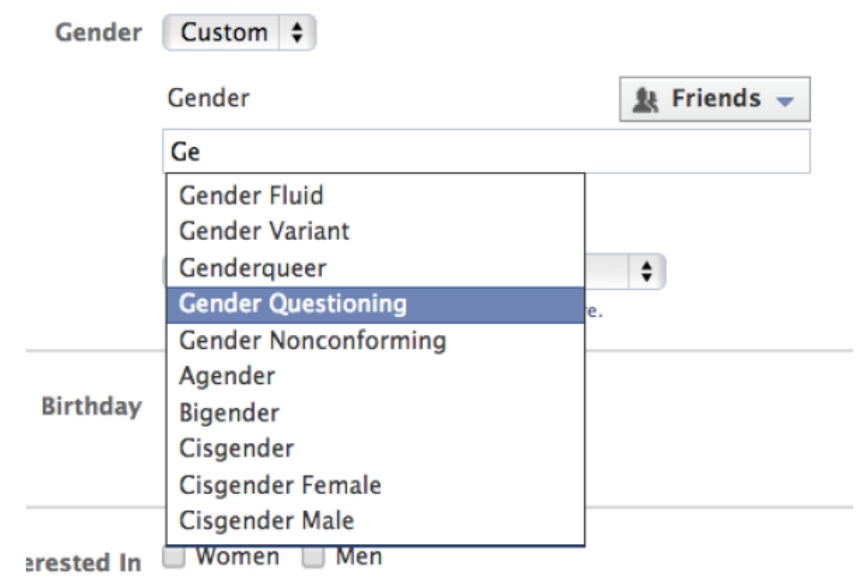

Butler (2008) teoriza que o gênero dos seres humanos é comunicado por meio de desempenhos sociais que envolvem, por exemplo, a adoção de certos estilos de vestimenta e tipos de acessório e maquiagem, mas o eu não é inerentemente masculino ou feminino. Sobre esse assunto, Viera (2005) explica que aspectos como família, sexo e nacionalidade não são escolhidos antes do nascimento, mas após vir ao mundo, inicia-se um complexo processo social de construção de identidade, no qual cada indivíduo pode manifestar diferentes inclinações, desejos e personalidade.

Aragão (2013, p. 08) explica que a transexualidade (ou a condição do ser trangênero) se refere ao "indivíduo que possui identidade de gênero diferente do sexo biológico designado na formação do feto", ressaltando que a construção da identidade de gênero está muito mais ligada aos aspectos simbólicos/sociais do que aos anatômicos.

Assim, pessoas que se identificam como transgênero podem ou não ter alterado seus corpos com cirurgias e/ou hormônios, e ainda serem reconhecidos como homem-trans (quando nasce com a anatomia feminina e se reconhece como homem) e mulher-trans (quando nasce com a anatomia masculina e se reconhece como mulher). No Brasil, um exemplo de pessoa transgênero é a cartunista e chargista Laerte Coutinho (Figura 02), conhecida por criar personagens como Gato e Gata, os Piratas do Tietê e Hugo. Em entrevista para o site IG, concedida em 2014, Laerte conta que, embora tenha nascido com sexo biológico masculino, assumiu sua identidade de mulher-trans em 2004, aos 57 anos, realizando algumas mudanças corpóreas e alterando suas escolhas de moda-vestuário para peças tidas como femininas (GIUSTI, 2014).

Figura 02: Cartunista e chargista Laerte Coutinho, antes e depois de assumir sua identidade transgênero (THERRIE, 2015).

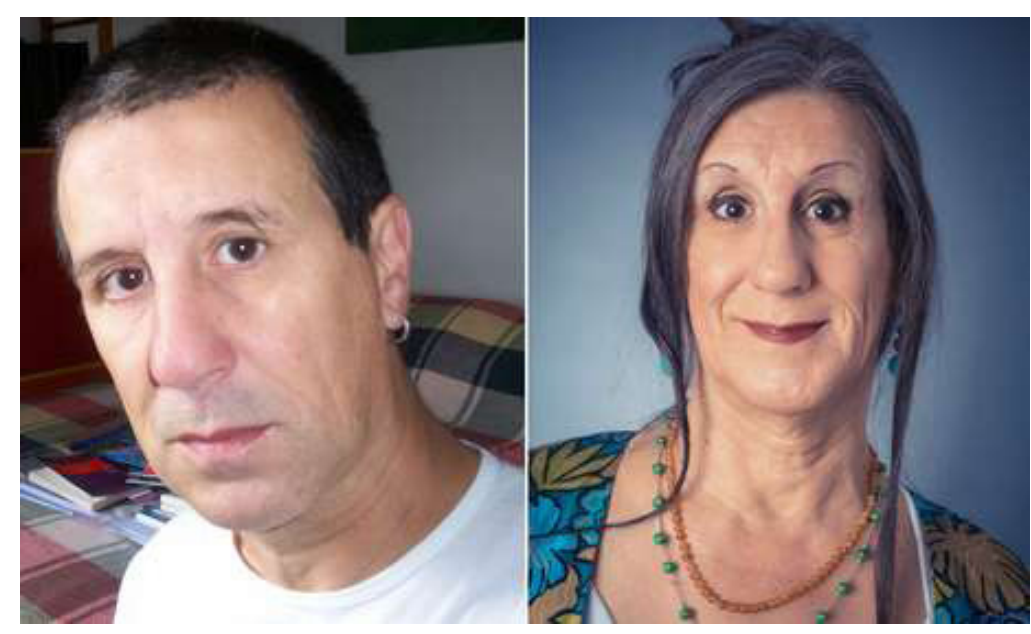


Ao problematizar o corpo e a subjetividade na transexualidade, Bento (2009) apresenta narrativas reais de indivíduos que se reconhecem como transgêneros, e relatam, entre outras coisas, como os artefatos de moda atuam em consonância com as mudanças corpóreas no processo de aceitação e descoberta de suas verdadeiras identidades. Dentre as revelações mais comuns, está o fato de que o "fracasso" em agir de acordo com as expectativas, ou seja, de não conseguir desenvolver o gênero "apropriado" para seu sexo, motivam vários episódios de agressões físicas e verbais por parte dos familiares.

Ao iniciar o processo de manifestação de um novo gênero, Bento (2009, p. 106) alude que as pessoas transgênero acabam adotando artifícios que "tentam dissimular os signos que 'os denunciam' como membros do gênero rejeitado", até conseguirem realizar os procedimentos médicos (hormonais/cirúrgicos) que ajustam ou removem as partes indesejadas. 0 autor explica ainda que

[...] a utilização de faixas que apertam os seios, técnicas para esconder o pênis, camisetas com gola alta para não mostrar o pomo de adão, perucas, maquiagens para disfarçar os sinais de barba são algumas das técnicas utilizadas na busca de uma coerência entre as performances de gênero e o corpo apropriado para desenvolvê-las (BENTO, 2009, p. 106-107).

Assim, é possível dizer que, para as pessoas transgênero, especificamente, a moda tem uma função determinante no processo de manifestação de uma identidade de gênero diferente da adotada até aquele momento perante a sociedade. Nesses casos, o estranhamento social se deve ao fato de envolver questões de ressocialização do indivíduo no âmbito familiar, amoroso e profissional, já que se trata de não somente assumir uma nova identidade de gênero, mas também de, muitas vezes, adotar outro nome e/ou pronomes de tratamento.

Nas formas de expressão do ser por meio da moda, artefatos de significação simbólica vêm passando por um processo de ressemantização corpórea, quando a adoção de vestuários/acessórios considerados típicos de cada gênero "criam comportamentos por sua capacidade de impor identidades sociais e permitir que as pessoas afirmem identidades sociais latentes" (CRANE, 2006, p.22).

No século XXI, após um período de discussões mais aprofundadas sobre o tema e com o fortalecimento sociopolítico da comunidade LGBT (Lésbicas, Gays, Bissexuais, Travestis, Transexuais e Transgêneros) outros termos surgiram para designar a pluralidade das identidades de gênero existentes. Cada um vem associado a particularidades distintas, que podem se adequar de forma mais democrática e inclusiva às pessoas que não são cis-gênero (classificação do homem ou mulher que nasceu com órgãos genitais correspondentes ao gênero que se expressam/reconhecem socialmente).

Dentre as categorias de maior representatividade entre a comunidade LGBT, selecionamos 3 para trazer à discussão: gênero neutro, andrógino e gênero fluido. Cada um desses termos se refere a grupos de indivíduos que identificam seu gênero de maneira particular, e encontram no mecanismo da moda-vestuário a forma mais confortável de se apresentar socialmente. É interessante perceber que tal temática já vem sendo estudada por diversas marcas, e propostas que fogem à dualidade feminino/masculino começam a surgir com mais frequência.

Herbenick \& Baldwin (2014) descrevem o gênero neutro como aquele em que a pessoa não se identifica com qualquer tipo de identidade de gênero. Esse termo também pode ser utilizado por alguém que, intencionalmente, não demonstra qualquer representação de gênero reconhecida, podendo inclusive buscar tratamentos hormonais e/ou cirurgias para fazer com que seus corpos não se adequem a nenhuma identidade de gênero. No campo da Moda, algumas propostas de vestuário surgem para atender a esse público, como a coleção de calçados da marca Melissa, cujo slogan é "Sem gênero, sem stress. A moda 
mais democrática do que nunca" (Figura 03).

Figura 03: Calçados da marca Melissa, lançados sem definição de gênero. Fonte: www.melissa.com.br

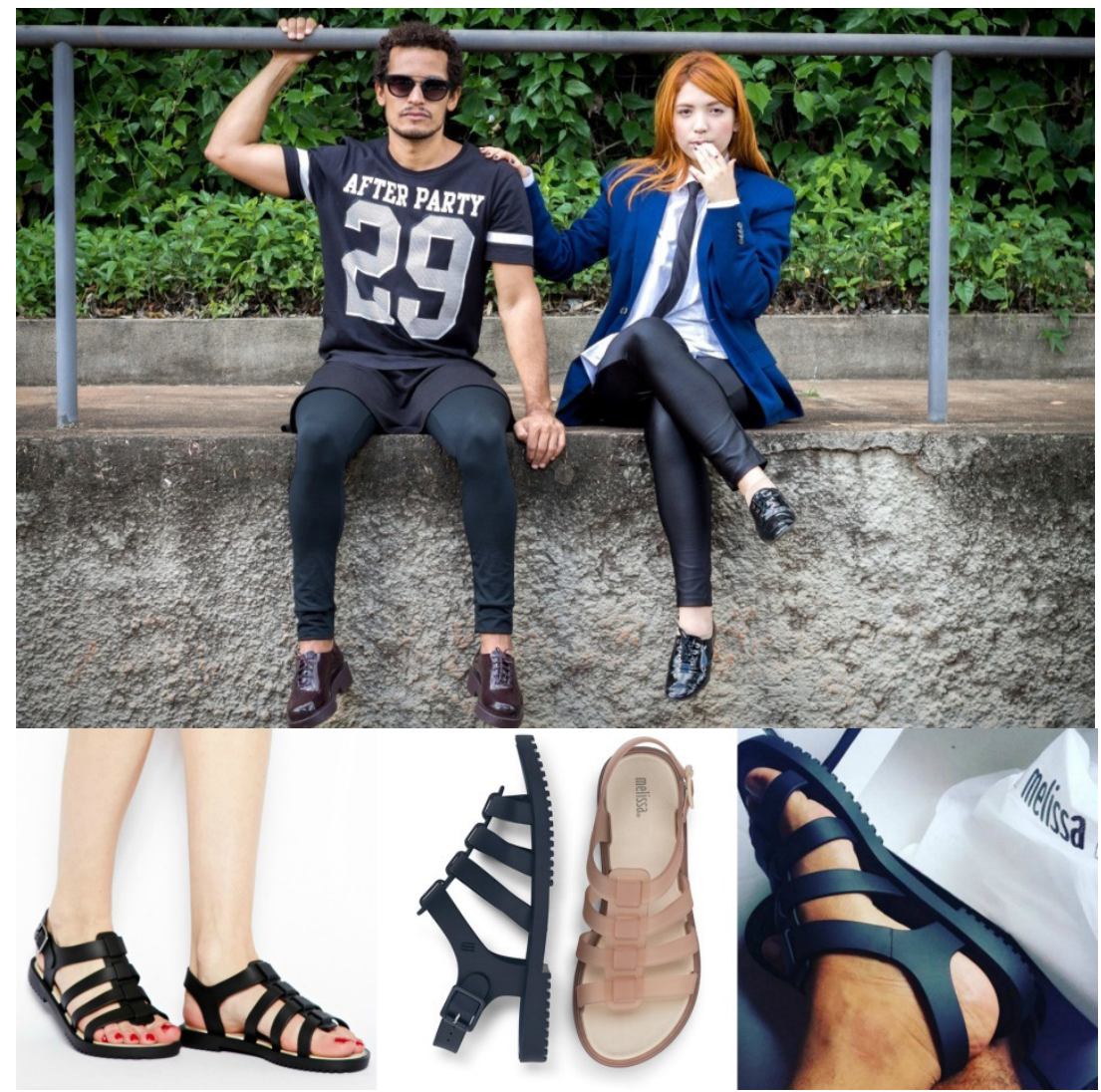

O termo andrógino se refere a alguém que não se identifica, nem se apresenta, como apenas homem ou mulher, mas incorpora qualidades masculinas e femininas, de modo que, num contexto social, provoque incertezas quanto ao gênero a que pertence. Alguns indivíduos andróginos se consideram pertencentes a um terceiro gênero separado que, intencionalmente, distorce, desafia ou transgride os papéis de gênero estabelecidos pela sociedade (HERBENICK \& BALDWIN, 2014). Exemplo de personalidade que ficou conhecida pelo seu aspecto andrógeno é Andreja Pejic (Figura 04), modelo sérvia que até 2015 se identificava como Andrej Pejic. Ela nasceu biologicamente homem, mas possuía características físicas, ligadas à aparência, que pertenciam tanto ao gênero masculino quanto ao gênero feminino (S MODA, 2013). Por conta de sua identidade de gênero, Andreja sente-se a vontade tanto com roupas feitas para o gênero feminino quanto para pessoas do gênero masculino. O fato de seu corpo não dar pistas claras sobre seu sexo, torna o impacto de suas escolhas mais suave no meio social.

Figura 04: Andreja Pejic, modelo sérvia conhecida por participar de desfiles e editoriais de moda tanto para coleções de roupas femininas quanto masculinas (5 Moda, 2013).

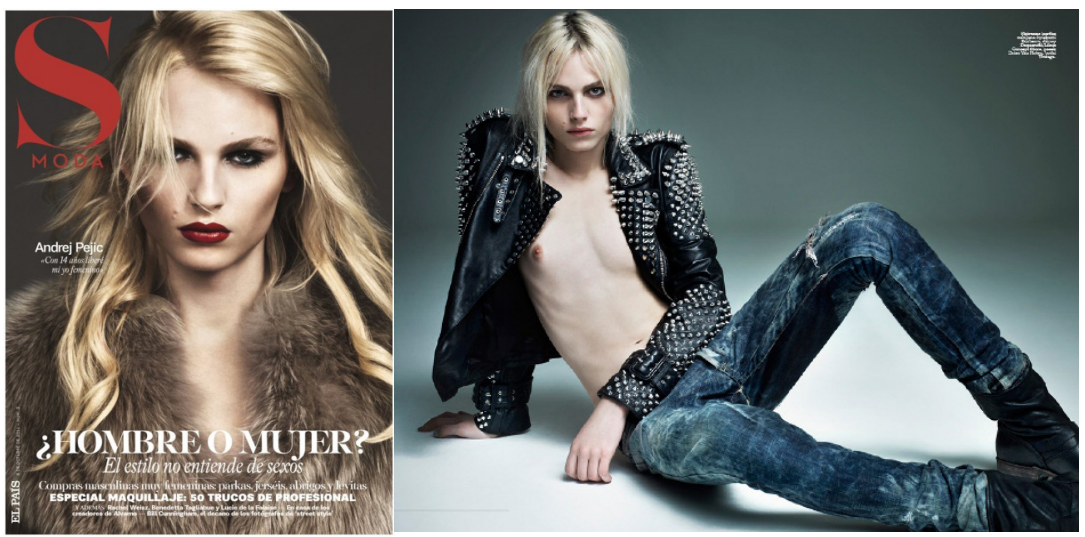


Já o gênero fluido está relacionado àquele (a) cuja identidade de gênero e apresentação não se limita a apenas uma categoria de gênero. Pessoas de gênero fluido podem ter compreensões dinâmicas ou flutuantes do próprio gênero, mudando de um para outro de acordo com o que sentir melhor no momento ou misturando representações que expressam masculinidade ou feminilidade (HERBENICK \& BALDWIN, 2014). Por exemplo, uma pessoa de gênero fluido pode se sentir mais como um homem num dia e mais como uma mulher no dia seguinte, ou sentir que nenhum dos termos se aplica a ela.

Revelação do cenário musical brasileiro, Liniker é um exemplo de pessoa que se reconhece no gênero fluido, e expressa essa identidade por meio da moda - usa saia, brincos, batom, colar, turbante, barba e bigode -, e reveza-se entre pronomes masculinos e femininos ao falar sobre si (Figuras 05 e 06).

Figura 05: Músico brasileiro Liniker, que se identifica com o gênero fluido, transita entre códigos sociais masculinos e femininos (Oliveira, 2016).

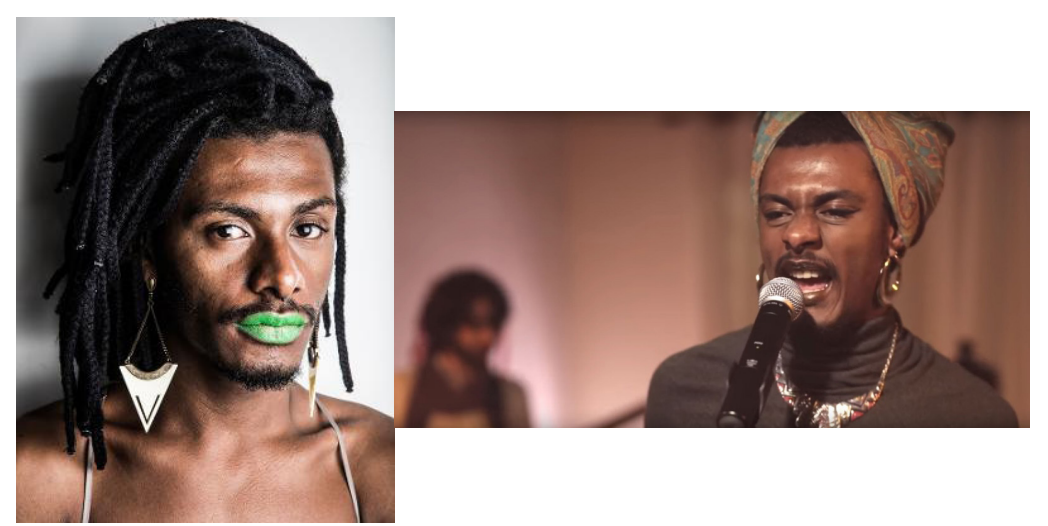

Figura 06: Brinco Liniker, parte da coleção Identidade (verão 2017) da marca de acessórios pernambucana Trocando em Miúdos. Peça homenageia a cantora brincando com a fluidez de gênero evocada (Trocando em Miúdos, 2017).

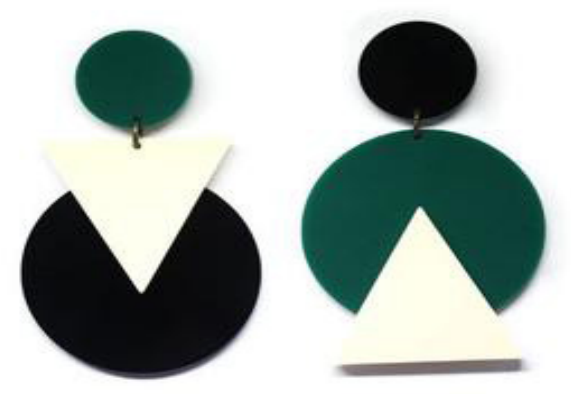

Assim, observando as manifestações de gênero apresentadas, verificamos que um dos primeiros aspectos decisivos no processo de representação social desses grupos se dá por meio da moda, quando o indivíduo decide assumir socialmente sua identidade não normativa.

\section{CONSIDERAÇÕES FINAIS}

No século XXI, quando a discussão de gênero e sexualidade se mostra mais aprofundada e aberta ao debate, Butler (2008, p. 59), alude que o gênero não deve ser entendido como um "conjunto de significados culturais inscritos num corpo nem a interpretação cultural de um corpo sexuado". Assim, o entendimento do ser homem ou ser mulher constitui-se a partir de um conjunto de normas instituídas, mantidas e 
repetidas sobre o corpo que geram essa aparência de substância, tornando as pessoas culturalmente viáveis (ou inviáveis).

O papel social da moda evidencia-se quando passa a integrar o processo de transformação social, que hoje, coloca em discussão os tradicionais sistemas normativos de gênero e dão espaço a novas formas de entender os tipos de representação contemporâneos. Nesses novos sistemas, "o feminino e o masculino não se organizam em termos binários”, e sim múltiplos e plurais (ZAMBRINI, 2016, p. 58). Para Zambrini (2016), a moda vem impulsionando uma abertura de pensamento sobre gêneros na medida em que provoca na sociedade um momento de reflexão sobre as formas de transgressão sociais:

\begin{abstract}
Atualmente, na moda, está se expressando um forte processo de mudança social e cultural em relação à construção dos gêneros. Por exemplo, as passarelas mais importantes têm hoje modelos transgêneros, além do surgimento de tendências que borram os limites tradicionais do feminino e do masculino nas propostas do vestir. Ou seja, o foco não é mais a biologia para pensar as identidades, e essa mudança é significativa justamente porque rompe com a ideologia binária do século XIX e nos permite falar sobre identidades no plural (ZAMBRINI, 2016, p. 58).
\end{abstract}

A importância das pessoas que assumem suas identidades de gênero não normativas publicamente, se dá quando passam a desempenhar um papel simbólico, de representatividade social. Esses grupos não são tidos como minoria por serem poucos, mas por estarem invisíveis nas instâncias de poder no âmbito sociocultural. Sua aparição em veículos midiáticos, muito além de criar polêmicas ou desencadear rejeições, tornase "exemplos dessa mudança cultural expressada no mundo da moda [...] e traz para as sociedades ocidentais novas formas de entender os corpos, as identidades e os gêneros" (ZAMBRINI, 2016, p. 59).

Embora ainda seja uma temática em construção, o design enquanto área de conhecimento acadêmico pode dar subsídios para o fortalecimento da transformação cultural social que vem acontecendo. Isso é possível quando dispõe de ferramentas capazes de quebrar estereótipos de gênero, e incentivar o desenvolvimento de projetos com perspectivas inovadoras e inclusivas, que permitam maior reflexão sobre os aspectos tangíveis e intangíveis do corpo e do uso social das vestimentas.

\title{
REFERÊNCIAS
}

ARAGÃO, R. Viagem Solitária: o Design de Produto para o Transhomem. 2013. Trabalho de Conclusão de Curso. Universidade Federal do Ceará, Juazeiro do Norte.

BENTO, Berenice. A diferença que faz a diferença: corpo e subjetividade na transexualidade. In: Bagoas, revista de estudos gays. Natal, EDFRN, volume 3, número 4, jan/jun de 2009, p. 95-112.

BUTLER, Judith. El gênero em disputa. El feminismo y la subversión de la indentidad. Traducción Ma. Antonia Muñoz. Barcelona: Paidós, 2008.

CASTILHO, Kathia. Moda e linguagem. São Paulo: Editora Anhembi Morumbi, 2004.

CASTILHO, Kathia. Do corpo presente à ausência do corpo: moda e marketing. São Paulo, 2004. Tese (Doutorado em Comunicação e Semiótica) - Pontifícia Universidade Católica de São Paulo.

CRANE, Diana. A moda e seu papel social: Classe, Gênero e identidade nas roupas. São Paulo: Editora Senac, 2006.

GIUSTI, I. Laerte: "Gostaria de não ter renegado minha homossexualidade por 40 anos”. 2014. Disponível em <http://igay.ig.com.br/2014-03-11/laerte-gostaria-de-nao-ter- 
renegado-minha-homossexualidade-por-40-anos.html>. Acessado em 15 de dezembro de 2016. 2005.

GREINER, C. O corpo: pistas para estudos interdisciplinares. São Paulo: Annablume,

HERBENICK, D.; BALDWIN, A. What Each of Facebook's 51 New Gender Options Means. 2014. Disponível em <www.thedailybeast.com/articles/2014/02/15/the-completeglossary-of-facebook-5-51-gender-options.html>. Acessado em 24 de setembro de 2016.

FABRI, H. J. P. Transgêneros na moda: design corporal e visibilidade "trans" na comunicação de moda. In: DOBRAS, Revista. São Paulo: Editora Estação das Letras, vol. 8, num. 17, maio de 2015, p. 46-54. 2003.

LE BRETON, D. Adeus ao corpo: antropologia e sociedade. Campinas: Editora Papirus,

OREMUS, Will. Here Are All the Different Genders You Can Be on Facebook. 2014. Disponível em <http://www.slate.com/blogs/future_tense/2014/02/13/facebook_ custom_gender_options_here_are_all_56_custom_options.html>. Acessado em 10 de outubro de 2016.

ROCHA, M. A. Reflexões sobre a inerência do corpo, do estilo de vida e da identidade no design de moda-vestuário. In: DOBRAS, Revista. São Paulo: Editora Estação das Letras, vol. 9, num. 19, junho de 2016, p. 62-75.

THERRIE, B. Crossdresser, travesti, trans: Laerte fala sobre sexualidade. 2015. Disponível em <https://www.terra.com.br/vida-e-estilo/mulher/comportamento/ crossdresser-travesti-trans-laerte-fala-sobre-sexualidade,c6d4497a0e2a8c81220e7b51 68cbObb15arfRCRD.html>. Acessado em 19 de dezembro de 2016.

VIEIRA, J. A. A identidade da mulher na modernidade. In: DELTA, São Paulo, v. 21, n. spe, p. 207-238, 2005. Disponível em <http://www.scielo.br/scielo.php?script=sci_ arttext\&pid=50102-44502005000300012\&lng=pt\&nrm=iso>. Acessado em 19 de dezembro de 2016.

ZAMBRINI, Laura. Olhares sobre moda e design a partir de uma perspectiva de gênero. In: DOBRAS, Revista. São Paulo: Editora Estação das Letras, vol. 9, num. 19, junho de 2016, p. 53-61. 